$$
\begin{aligned}
& \frac{29}{11.12 \cdot 80}+4+24015 \\
& \text { SAND79-2212 }
\end{aligned}
$$

\title{
Creep Consolidation of Nuclear Depository Backfill Materials
}

Barry M. Butcher

4

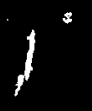

Sandia National Laboratories 
SAND79-2212

Unlimited Release

CREEP CONSOLIDATION OF NUCLEAR DEPOSITORY BACKFILL MATERIALS

\author{
B. M. Butcher \\ Geomechanics Division 5532 \\ Sandia National Lrboratories \\ Albuquerque, New Mexico 87185
}

\begin{abstract}
Evaluation of the effects of backfilling nuclear waste repositury rooms is an fmportant aspect of waste repository design. Consolidation of the porous backfill takes place as the room closes with time, causing the supporting stress exerted by the backflll against the intact rock to increase. Estimation of the rate of backfill consolidation is required for closure rate predictions and should be possible if the creep law for the solld constituent is known. A simple theory describing consolidation with a spherisal vold model is derived to illustrate this relationship. Although the present form of the theory assumes a homogeneous isotropic incompressible materlal atyplcal of most rocks, it may be applicable to rock salt, which exhibits considerable plasticity under confined pressure. Application of the theory is illustrated assuming a simple steady-state creep law, to show that the consolidation rate depends or the externaliy applied stress, temperature, and porosity.
\end{abstract}

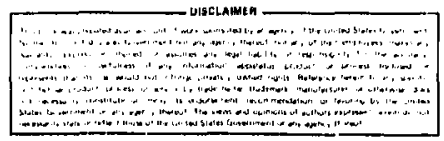


Table of Contents

Introduction $\ldots \ldots \ldots \ldots \ldots \ldots \ldots \ldots \ldots \ldots \ldots \ldots \ldots \ldots \ldots \ldots \ldots \ldots$

Model Description $\ldots \ldots \ldots \ldots \ldots \ldots \ldots \ldots \ldots \ldots \ldots \ldots \ldots \ldots \ldots \ldots \ldots, 10$

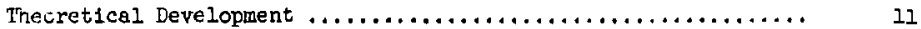

Equivalent Stress and strain ..................... 11

Compaction Equations ............................ 14

Examples $\ldots \ldots \ldots \ldots \ldots \ldots \ldots \ldots \ldots \ldots \ldots \ldots \ldots \ldots \ldots \ldots \ldots \ldots \ldots \ldots \ldots \ldots \ldots \ldots \ldots$

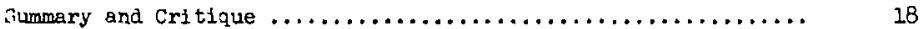

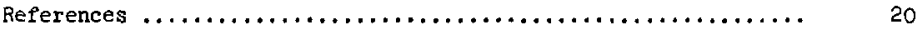


List of Symbols

$$
\sigma_{1 j}
$$$$
\sigma_{1 j}
$$

$\varepsilon_{1 j}$

$\underset{\epsilon_{1 j}}{P}$

$\sigma_{1}, \sigma_{2}=\sigma_{3}$

$$
\begin{aligned}
& \varepsilon_{1}, \varepsilon_{2}=\varepsilon_{3} \\
& d \varepsilon_{1}, d \varepsilon_{2}=d \varepsilon_{3} \\
& d \varepsilon_{1}^{P}, d \varepsilon_{2}^{P}=d \varepsilon_{3}^{P}
\end{aligned}
$$

$$
\sigma_{r}, \sigma_{\phi}=\sigma_{\theta}
$$

$$
\begin{aligned}
& \epsilon_{r}, \varepsilon_{\phi}=\epsilon_{\theta} \\
& d \varepsilon_{r}, d \varepsilon_{\phi}=d \varepsilon_{\theta} \\
& d \varepsilon_{r}^{P}, d \varepsilon_{\phi}^{P}=d \varepsilon_{\theta}^{P}
\end{aligned}
$$

$$
-\mathrm{P}
$$$$
\overline{\mathrm{de}}^{\mathrm{P}}
$$

$\overline{0}$

$\dot{\varepsilon}_{1}$

t
True stress

True deviatoric stress

True strain

True plastic strain

True stresses in the triaxial loading configuration

True strains, strain increments, and plastic strain increments in the triaxial loading configuration

True stresses in the spherical shell configuration

True atrains, strain increments, and plastic atrain increments in the spherical shell configuration

Equivaleat plestic strain

Equivalent plegtic strain increment

Equfvalent otress

True axial atrain rate in the triaxial loading configuration

Time

Temperature 


\section{L1st of Symols (Cont.)}

$\dot{\mathbf{5}}$

$a, a, b, b$

$\pi$

$\dagger_{1}$

$A, B, Q, R$, $M$, and $n$ $\frac{d r}{d t}$

See F1gure 1

Poroa1ty

$\frac{d r}{d t}$

Constants iv the siuple creep model given by Equation (3.1) 


\section{Introduction}

Evaluation of the effects of backfilling nuclear waste disposal rooms is an important aspect of waste repository programs. Backfilling is proposed for number of reasons, among which are greater isclation of the waste and reduction of subsidence. Barriers to radionuclide migration are also possible by proper selection of backfill material. All of these features have in common the requirement that the rate of consolidation of the backfill must be determined because the backfilled region, between the heat source (the waste container) and the structural comzonents of the repository, influences heat flow, transmissivity of fluids, and the extent of deformation of the structure itself. Complete elimination of porosity during backfilling operations is believed to be virtually impossible. Therefore, structural response and permesblity calculations require a constitutive relationship for a porous material in a tempersture fleld with an externally applied pressure (imposed by creep of the solld rock surrounding the repository). A considerable advantage will be gained in the development of these const1tutive relation if the creep consolidation of the porous material can be described in terms of the creep characteristics of its solid constituent. Suecess in this approach minimizes the need for a large and costly material teating program to eutublish the creep propertieg of materials of varying porosity all composed of the same solld.

The relationship between dynamic inelastic compaction of a porous solsd and deformation of 1ts solld matrix has been considered in detall in shock mitigation otudies. (1) The possibility exists, therefore, of addressing creep consolidation of porous materials in an 1dentical manner. 
The purpose of this report is to suggest a theoretical approach by which such a constitutive model can be developed.

The example discussed assumes voids in the material becone appraxtmately spherical in shape after a short translent perlod. Some justification for these assumptions can be made for rock salt, which is being considered for backfilling WIPP waste disposal rooms, because salt deforms in a manner similar to metals under certain conditions. The theory in a more advanced state can be extended to other vold geometries and the incompressibility assumption, which in part satisfies the conditions of

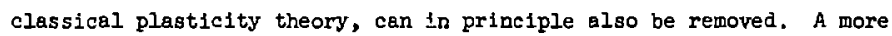
general theory of elastic materials with volds is also available. (2) These more complex questions are not addressed in this paper.

\section{Model Description}

The compaction model ia bosed on the symetric collapse of a hollow sphere of homogeneous isotropic incompressible elastic-plastic material. A time-dependent pressure $P(t)$ is applied to the outer boundary while the Inner boundary remains stress free es shown in F'lgure 1. The porous aggregate is Imagined to be a three dimensional array of these spheres, with the outer boundaries overlapping so that the only void volume is that of the sphertcal volds. These volds are considered noninteracting so that the pressure supported by the spheres is assumed to be the pressure supportec by the porous aggregate.

In the actual backfilling process, the aggregate is usually composed of sharp angular grains of rock which fit together in randow orientations to cause a porosity in many cases of $60 \%$ or greater, vibratory compection 
can decrease the vold volume to some extent, but clearly the volds are far from spherical. This does not completely discredit the model, however, because as further conpaction occurs by creep the voids should become more spherical in nature. The progression to more spherical shoped volds is implied by the tendency of the volds to minimize their surface area. In practical application of the theory, therefore, it is necessary to obtain the initial compaction response experimentally up to the time wher the voids have developed sufficient sphernidicity. This partially deformed atate can then be used as an Initial condition for the spherical vold analysis. Such an approach is quite consistent with our objectives, because it is the long term response of the backfill that we seek to model. Very long duration experiments are usually not conducred in great numbers, and yet the later siages of such experiments are precisely the realm where the spherical vold model is expected to glve realistic predictions.

\section{Theoretical Developuent}

\section{a) Equivalent Stress and Strain}

The creep compaction equation derived in this section depeids on the application of data from triaxial loading creep experiments to the radially symmetric spherical shell pore collnpse model. (3) A similar analysis for cylindrical voids can be developed uising a solution for creep of a tube under pressure Blven in Reference 4, In triaxial creep experiments, an axial atress $\sigma_{1}$ is applied to right clrcular cylindrical sample surrounded by a lateral hydrostatic presaure. Stresses and 
strains for this configuration are therefore (see List of Symbels for symbol definitions):

$$
\left(\sigma_{1}, \sigma_{2}=\sigma_{3}\right),\left(\mathrm{d} \varepsilon_{1}, \mathrm{~d} \varepsilon_{2}=\mathrm{d} \varepsilon_{3}\right) .
$$

The spherical shell wodel, on the other hand, is described by the following stresses and strains:

$$
\left(\sigma_{r}, \sigma_{\emptyset}=\sigma_{\theta}\right) \quad, \quad\left(d \varepsilon_{r}, \mathrm{~d} \varepsilon_{\emptyset}=\mathrm{d} \varepsilon_{\theta}\right)
$$

A relationship between these two geometrical configurations can be obtained by the classical plasticity method of defining plastic deformation in terms of the plastic strain increment $\overline{\mathrm{de}}^{\mathrm{P}}$ and the equivalent stress $\vec{\sigma}$. The equivalent plastic strain $\bar{\varepsilon}^{\mathrm{P}}$ is defined as:

$$
\bar{\epsilon}^{P}=\int \frac{d_{c}}{P}
$$

where

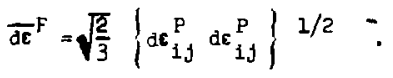

In teras of the princlpal strains,

$$
\overrightarrow{\mathrm{d}}^{\mathrm{P}}=\sqrt{\frac{\sqrt{2}}{3}}\left\{\left(\mathrm{~d} \varepsilon_{1}^{P}\right)^{2}+\left(\mathrm{d} \varepsilon_{2}^{P}\right)^{2}+\left(\mathrm{d} \mathrm{e}_{3}^{P}\right)^{2}\right\} 1 / 2 .
$$

w:th ali otruins expressed as true (or logarlthmic) strains. If the

"Subscipts 1,2 , and 3 are used instead of $I, A$, and $z$ because the published material data and conatitutive equations have been presented in this form. 
condition is added to this definition that no volume change occurs during creep,

$$
\mathrm{de}_{11}^{\mathrm{P}}=0
$$

the plastic atrain increments for the two configurations under consideration are given by:

$$
\mathrm{d}_{1}^{\mathrm{P}}=-2 \mathrm{~d} \varepsilon_{2}^{\mathrm{P}}=\overline{\mathrm{d \varepsilon}}^{\mathrm{P}}
$$

and

$$
d \varepsilon_{F}^{P}=-2 d \varepsilon_{q}^{P}=\overline{d \varepsilon}^{P}
$$

The axial strain increment in the triaxial loading test is therefore equal in magntude to the radial strain increment in the collapse of spherical shells and:

$$
\vec{C}=\varepsilon_{r}^{P}=\varepsilon_{1}^{P}
$$

The equivalent stress is detined by:

$$
\left.\bar{\sigma}=\sqrt{\frac{3}{2}} \mid \sigma_{i j} \sigma_{1 j}\right\}^{1 / 2},
$$

or in terms of principal stresses

$$
\bar{\sigma}=\sqrt{\frac{1}{2}}\left\{\left(\sigma_{1}-\sigma_{2}\right)^{2}+\left(\sigma_{2}-\sigma_{3}\right)^{2}+\left(\sigma_{1}-\sigma_{3}\right)^{2 / 1 / 2} \cdot(2,4 b)\right.
$$

This definition shows that the equivalent atreas fot spherical shell 
collapse; equal to the stress difference $\left(\sigma_{r}-\sigma_{\theta}\right)$, and for triaxinl tests is 1 s equal to i2s stress difference $\left(\sigma_{1}-\sigma_{3}\right)$.

\section{b) Compaction Equations}

Three equations are required to define the collapse of a spherical vold with time. Two of these equations, the equilibrium condition and the relationship between plastic strain and instantaneous porosity, define the extent of compaction and the externaliy applied stress at any given time. The tbird equation, the creep law for the solid materiai, liefines the stress that can be supported by the solid as a function of temperature and time. For simplicity, these equations will be discussed starting with the creep law, then the equilibrium condition, and finally the plastic strain relationship.

Creep constitutive equations are generally of the form $(5)$

$$
\dot{s}_{1}=\dot{\varepsilon}_{1}\left(\bar{\sigma}, \Sigma_{1}, T\right),
$$

where $T$ is the temperature. The effective stress $\bar{\sigma}, \operatorname{stra1n} c_{1}$, and temperature $T$ are functions of $t$, the time, relative to some initial state of the material. The strain $\varepsilon_{1}$ in this equation is assumed to be completely nonelastic in nature in the present analysis: 1.e., elastic strains are consldered negliglble. Furthernore, a yield polnt or a threshold value for $\bar{\tau}$, below which no creep occurs, has yet to be established as physically realiatic and so will not be considered. Next, the equilibrium equation for a spherical shell,

$$
r \frac{d \sigma_{r}}{d r}+2\left(\sigma_{r}-\sigma_{\theta}\right)=0
$$


is written in terms of the equivalent stress to obtain

$$
r \frac{d \sigma_{r}}{d r}+2 \bar{\sigma}=0 .
$$

The creep law, Equation (2.5) muat be solved for $\bar{\sigma}$, the result substiticed into Equation (2.7), and then Equat. n (2.7) must be integrated to obtain the value of $\sigma_{r}$ at $r=b$ (Figure 1) in order to find the externally applied stress that the porous solid can support. Before this step is possible, however, a relationship between $\varepsilon_{1}$, the plastic strain increment, and $r$ is required.

In the absence of any yleld point for the solid material, the true strain increment d $\varepsilon_{g}$ of radially symmetric deformations is given hy

$$
d \varepsilon_{G}=\frac{d}{c},
$$

and, according to Equation $(2.2 \mathrm{c})$, is 4 lso related to the equivalent plestlc ctrain de $\mathrm{e}=-\frac{\frac{\mathrm{d}^{\mathrm{e}}}{2}}{\mathrm{P}}$. Next, the equivalent strain is related to the strain $\varepsilon_{1}$ of the creep law, (2.2b) so that the relationship between the otrain rate $\dot{\varepsilon}_{1}$ and $\dot{\dot{r}}$ ie

$$
\dot{\varepsilon}_{1}=\dot{\vec{\varepsilon}}^{\mathrm{P}}=-2 \frac{\dot{r}}{r}
$$

Equation (2.8b) can be integrated to give

$$
\varepsilon_{1}=\bar{e}^{P}=-2 \ln \frac{r}{F_{0}},
$$

Which in turn can be further afmplified by evoking the constant volume condition in the form 


$$
r_{0}^{3}-r^{3}=a_{0}^{3}-a^{3}=b_{0}^{3}-b^{3} .
$$

so that

$$
\varepsilon_{1}=-2 \ln \left\{\frac{r^{3}}{r^{3}-\left[a^{3}-a_{0}^{3}\right]}\right\} \text {. }
$$

One can also show that the porosity ${ }^{\ddagger}$ lo related to the diansions of the spherical shell according to

$$
\begin{gathered}
n=\frac{a^{3}}{b^{3}}, \quad \pi_{0}=\frac{a_{0}^{3}}{b_{0}^{3}}, \\
a^{3}=\frac{\eta}{[1-\eta]} \frac{\left[1-\pi_{0}\right]_{a_{0}^{3}}}{\pi_{0}},
\end{gathered}
$$

and

$$
b^{3}=\frac{1}{[1-\pi]} \frac{\left[1-\eta_{0}\right]}{\eta_{0}} a_{0}^{3},
$$

where $r_{0}$ is the initial porosity. The strain rate $\dot{\varepsilon}_{1}$ from (2.8b) is related to the rate of change of porosity by

$$
\dot{\varepsilon}_{1}=-\frac{2}{3} \frac{\hat{\eta}_{1}}{\eta_{0}} \frac{\left[1-\eta_{0}\right]}{[1-\eta]^{2}} \frac{a_{0}^{3}}{r^{3}} .
$$

Forosity is defined as the fraction of the total volume occupled by the voids. This analysis is not sophisticated enough to consider packing factars and ather microscopic vold configuration detalls, all of which are embedded in the porosity parameters. 
Equations (2.5), (2.7), and $(2.8 a)$ or 1ts various forms define the compaction law. In applying these equations (2.7) is integrated asouming a stress free condition at the inner vold surface to obtain the stress on the outer boundary,

$$
\sigma_{r=b}=-\int_{a}^{b} 2 \frac{\vec{g}}{r} d r,
$$

and the compaction stress is defined as

$$
P(t)=-\sigma_{r=b} \quad .
$$

\section{Examples}

Creep response of geological materials is of ten observed to exhibit all three primary, secondary and tertiary stages of creep. For simplicity, however, application of the compaction theory will be illustrated with a simple steady-state creep law: $(5,6)$

$$
\dot{\theta}_{1}=B e^{-\frac{Q}{\mathrm{RT}}}\left(\frac{\bar{\sigma}}{\mu}\right)^{1 / n}
$$

where $B, Q, R, \mu$ and $n$ are constants. This law states that the steadystate creep rate is dependent only on the instantaneous values of the temperature and the effective stresa, both of which in the general case are time dependent. The next assumption is that (3.1) is a single valued function of the stress so that it can be fnverted to

$$
\bar{\sigma}=\mu\left(A e^{\frac{Q}{R T} \dot{E}_{1}}\right)^{n}
$$

where $A=B^{-1}$ is a constant. This equation and the atrain-rate equation 
(2.12) can now be substituted into (2.13) to compute the pressure applied $\therefore$ the outer boundary of the spherical shell:

$$
\sigma_{r=b}=-2 \mu \int_{a}^{b}\left[\frac{2 A\left[-\dot{\eta}_{0}\left[1-\eta_{0}\right] e^{\frac{Q}{R T}}\right.}{3 \eta_{0}\left[1-\eta_{0}\right]^{2}} \frac{{ }^{3}}{r^{3}}\right]^{n} \frac{d r}{r}
$$

Since $t$ and $r$ depend on $2 y$ on $\dot{a}, \dot{b}$, and the current shell dimensions, $(3 . \dot{j})$ can be integrated to give the compaction stress

$$
P(t)=-\sigma_{r=b}=\frac{2 u}{3 n}\left[\frac{\left.2 A e^{\frac{Q}{R T}}(-\dot{\eta})\right]}{3[1-\eta]}\right]^{n}\left[\frac{1-\eta^{n}}{\eta^{n}}\right] .
$$

There are two simple ways of examining the implications of this result: (1) the rate of change of porosịty at constant temperature can be assumed constant and various stress-porosity (or stress vs tiae) curves , computed, (2) the external stress can be assumed constant and the porosity computed as a function of time. Computational results for both $.1 \cdots, \ldots$ have been platted in Figures 2 and 3 using ressonable values for the various material constants. Material constant values $(5,6)$ for these computations are tabulated in Table 1. The fact that infinite stress is required to completely eliminate all porosity ia a natural consequence of this type of analysia.

\section{Summary and Critique}

The main objective of this report is to suggest that the creep consolidation of a porous rock can be estimated from the creep properties of the solid constituent from which $1 \mathrm{t}$ is formed. The theoretical approach has been illustrated with a simple spherical void model of ar. 
homogeneous isotropic incompressible elastic-plastic material. While there assumptions are clearly oversimplifications of most granular materials, there may be some substance to the theory when rock salt is the backfilling material. Application of the theory is illustrated with a very simple steady-state creep law found to describe some parts of the creep of WIPP rock salt at elevated temperatures.

Application of the theory is also clouded by the fact that the initial state of the backflll is ept to contain highly irregular voids. Additional laboratory information is required under such circumstances, to experimentally define compacition response up to the polnt where the volds become more spherical in neture, if, in fect, they ever do.

Perhaps the biggest constraint on the current theory is imposed by the incompressibility restriction in connection with clasalcal piasticity. Thus, this theory cannot offer any guidance in the consolidation of granular materials when fracture is an important mode of deformation. Dilation during inelastic deformation is a fracture related phenomenon which likewise does not fit withis the fromework of the present theory. If, on the other hand the rock exhibits some degree of plasticity, then the present theory may be of some assistance in predicting the extent of consolidation over a glven time period. 


\section{References}

1. "Shack-Wave Compaction of Porous Aluminum," B. M. Butwer, M. M. Carroll, and A. C. Holt, J. Appl. Phys., 45, No. 9, pp. 3864-3875, 1974 .

$\therefore$ "A Nonlinear Theory of Elastic Materials with Volda," J. W. Nunziato as.s itephen c. Cowin, Arch. Rat. Mech, 72, pp. 175-201.

3. "Compression of a Spherical Shell of Work-Hardening Matertal," P. Chadw1ck, J. Mech. Sc1., 5, pp. 165-182, 1963.

4. Strength of Materials, A. A. Ilyushin and V. S. Lensky, Fergamon Press, London, pp. 284-286, 1967.

5. "Prelimimary Deformation-Mechanism Map for Salt (With Application to WIPP)," D. E. Munson, Sand1a Laboratorles Report SARD79-0076, January 1979.

6. "Constitutive Model for the Low Temperature Creep of Salt (With Application to WIPP!," D. E. Munson and P. R. Dawson, Sandia Laboratories Report SAND79-1853, October 1979. 
Table 1: Rock Salt Material Constants

$$
\begin{aligned}
& B=6.47 \times 10^{13} / \mathrm{s} \\
& Q=0.042 \mathrm{MJ} / \mathrm{mol}(10 \mathrm{kcal} / \mathrm{mol}) \\
& \mathrm{B}=0.2 \\
& \mu=9.62 \mathrm{GPa} \\
& \mathrm{R}=8.317 \mathrm{~J} / \mathrm{mol}^{\circ} \mathrm{C}
\end{aligned}
$$




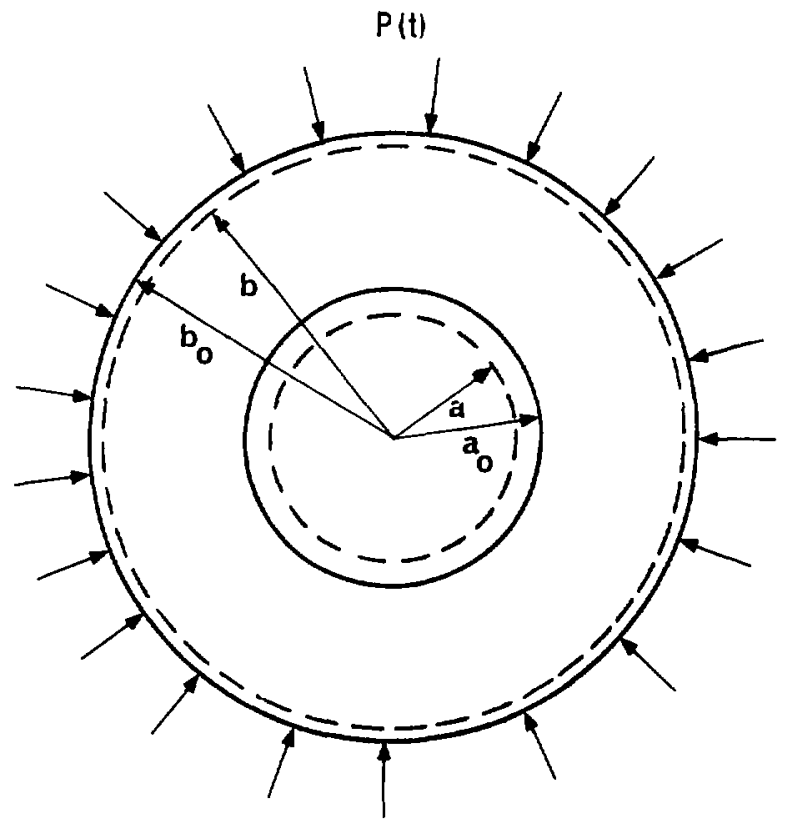

Flgure 1: Sphericel vold model 


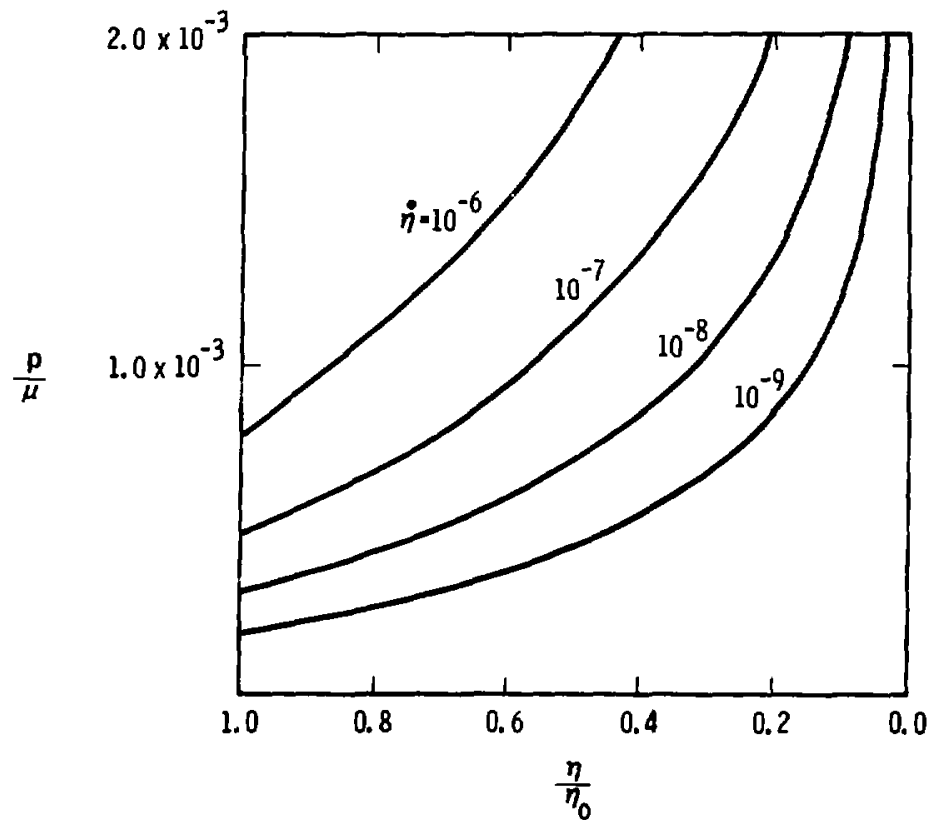

Flgure 2: Reduced pressure-poronity curves for var1oun values of conatent competion

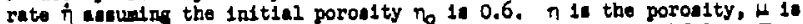
the beer modulu and $P$ is the presaure apported by the backfill. The fact that the preseure bocomed infint te as porosity eppronche zero is - cowor fecture of ipherical vold modela. 


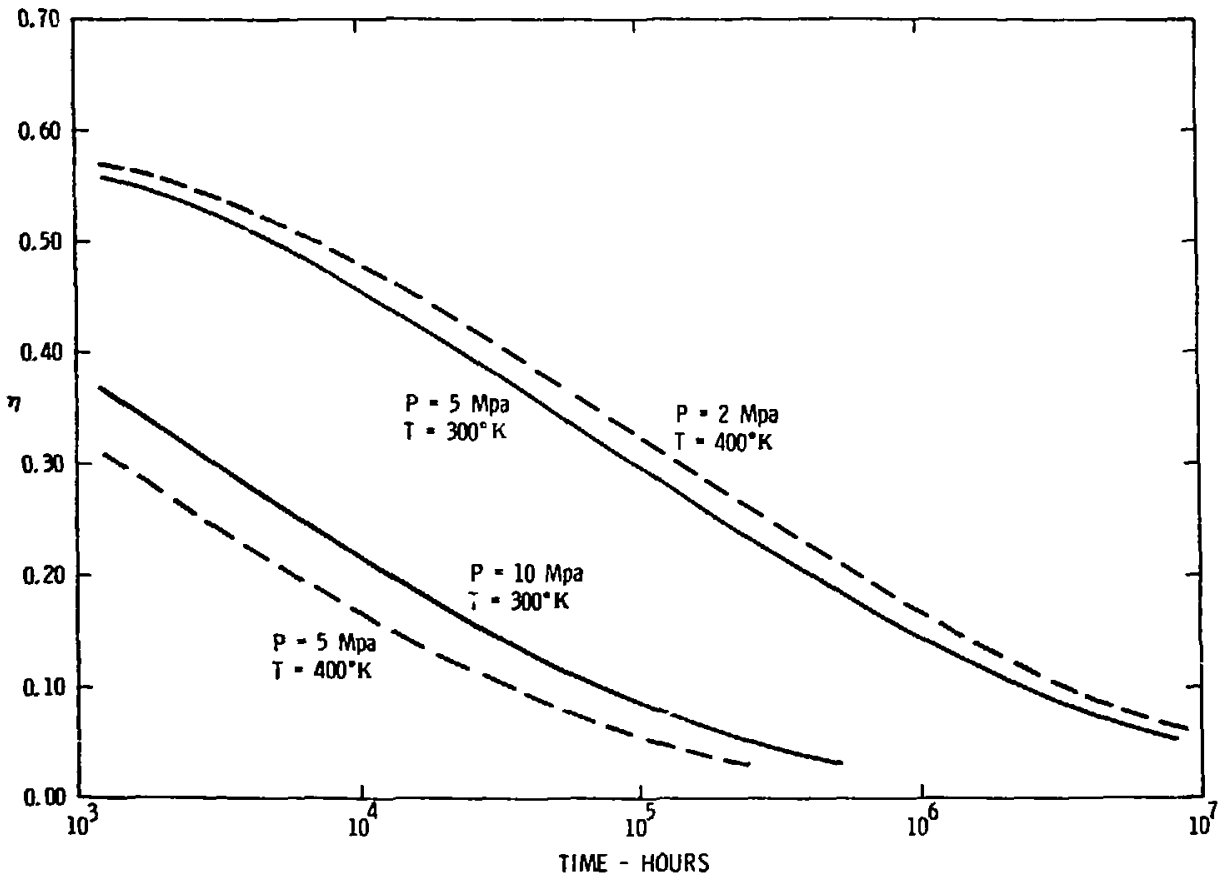

Figure 3: Conollantion time for various values of constant pressure $P$ and temperature $T$. $T$ is the porosity and an intilal porosity $\eta_{0}$ of 0.6 is asaumed. The time to achieve complete compecton is infinite for spherical roid models. 